\title{
THE PATHOLOGY OF ASTHMA, WITH SPECIAL REFERENCE TO CHANGES IN THE BRONCHIAL MUCOSA
}

\author{
BY \\ M. S. DUNNILL \\ From the Department of Pathology, the Radcliffe Infirmary, Oxford
}

(RECEIVED FOR PUBLICATION AUGUST 14, 1959)

\begin{abstract}
The pathological features of 20 cases dying in status asthmaticus have been studied. In gross sections the lungs showed no emphysema, but mucus plugs in the air passages and focal areas of collapse were outstanding features. Five cases showed cystic bronchiectasis which was of a similar distribution to the focal areas of collapse, occurring in the upper lobes as commonly as in the lower lobes.

Histologically, shedding of the ciliated bronchial mucosal cells was prominent and this is attributed to a transudation of oedema fluid from the submucosa. Areas of regeneration of the mucosa, with the presence of simple stratified epithelium, were seen frequently. The loss of the ciliated respiratory epithelium and the transudation of oedema fluid into the bronchial lumen, with interference with the action of the remaining ciliated cells, are considered to be the essential factors in the failure of clearance of the bronchial secretions in asthma. It is postulated that bronchospasm plays little or no part in the shedding of the bronchial mucosa or in the pathogenesis of the asthmatic attack.
\end{abstract}

As long ago as 1883 Curschmann noted the presence of ciliated columnar respiratory cells in the sputum of patients suffering from asthma. Ellis (1908) observed detachment of the bronchial mucosa, with consequent ulceration of a blood vessel, in a necropsy on a patient dying in status asthmaticus. Houston, De Nevasquez, and Trounce (1953), in a clinico-pathological study of nine fatal cases of asthma, mentioned partial or complete detachment of the bronchial mucosa as a constant finding. The epithelium was intimately mixed with mucus and eosinophils and assisted in plugging the bronchial lumen. They considered that this detachment of the epithelium was due to a mechanical separation consequent upon contraction of the bronchial muscle. The crenation of the bronchial wall was taken as evidence of muscle spasm, but the illustrations purporting to show this were not altogether convincing. It was to see if some other more logical explanation of the necropsy findings in asthma could be found that the following series of cases was studied.

\section{Material}

Lungs collected at necropsy from 20 patients dying in status asthmaticus have been examined. The lungs were fixed by perfusion with $10 \%$ formol saline through the main bronchus or, where this was not feasible because the bronchus was completely blocked by mucus, through the pulmonary artery. Up to 20 blocks of tissue were examined from each lung, and sections were stained with haematoxylin and eosin, Weigert's haematoxylin and Van Gieson, by

TABLE I

CLINICAL DETAILS OF CASES

\begin{tabular}{|c|c|c|c|c|c|}
\hline $\begin{array}{l}\text { Case } \\
\text { No. }\end{array}$ & $\begin{array}{l}\text { Age } \\
\text { (yr.) }\end{array}$ & Sex & $\begin{array}{l}\text { Duration of } \\
\text { Disease (yr.) }\end{array}$ & $\begin{array}{l}\text { Family } \\
\text { History }\end{array}$ & $\begin{array}{l}\text { Special Features } \\
\text { in Lungs }\end{array}$ \\
\hline $\begin{array}{l}1 \\
2 \\
3 \\
4 \\
5 \\
6 \\
7 \\
8\end{array}$ & $\begin{array}{c}10 \text { mths. } \\
4 \\
10 \\
15 \\
21 \\
24 \\
25 \\
27\end{array}$ & $\begin{array}{l}\mathbf{F} \\
\mathbf{F} \\
\mathbf{F} \\
\mathbf{F} \\
\mathbf{F} \\
\mathbf{F} \\
\mathbf{M}\end{array}$ & $\begin{array}{c}2 \text { mths. } \\
1 \frac{1}{1} \\
6 \frac{1}{2} \\
13 \frac{1}{2} \\
19 \\
21 \\
22 \\
25\end{array}$ & $\begin{array}{l}\text { Nil } \\
+ \\
\text { Nil } \\
+ \\
+ \\
+ \\
+ \\
\text { Nil } \\
,\end{array}$ & $\begin{array}{c}\cdots \\
\overline{-} \\
= \\
\overline{-} \\
\begin{array}{c}\text { Bronchiectasis and } \\
\text { scattered nodular } \\
\text { fibrosis }\end{array}\end{array}$ \\
\hline $\begin{array}{r}9 \\
10 \\
11 \\
12 \\
13 \\
14 \\
15 \\
16 \\
17 \\
18 \\
19 \\
20\end{array}$ & $\begin{array}{l}28 \\
29 \\
34 \\
38 \\
41 \\
43 \\
44 \\
50 \\
54 \\
56 \\
64 \\
67\end{array}$ & $\begin{array}{l}\mathbf{M} \\
\mathbf{M} \\
\mathbf{M} \\
\mathbf{F} \\
\mathbf{F} \\
\mathbf{F} \\
\mathbf{F} \\
\mathbf{M} \\
\mathbf{F} \\
\mathbf{M} \\
\mathbf{F} \\
\mathbf{F}\end{array}$ & $\begin{array}{c}26 \\
25 \\
9 \\
32 \\
\text { Many years } \\
4 \\
30 \\
18 \\
27 \\
4 \\
3 \\
30\end{array}$ & $\begin{array}{l}+ \\
+ \\
+ \\
\text { Nil } \\
\text { ", } \\
\ddot{+} \\
+ \\
\stackrel{+}{\text { il }} \\
\text { ", } \\
\text { ", }\end{array}$ & $\begin{array}{c}\overline{-} \\
\text { Bronchiectasis } \\
\text { - } \\
\text { Bronchiectasis } \\
\text { Bronchiectasis } \\
\text { - } \\
\text { - }\end{array}$ \\
\hline
\end{tabular}




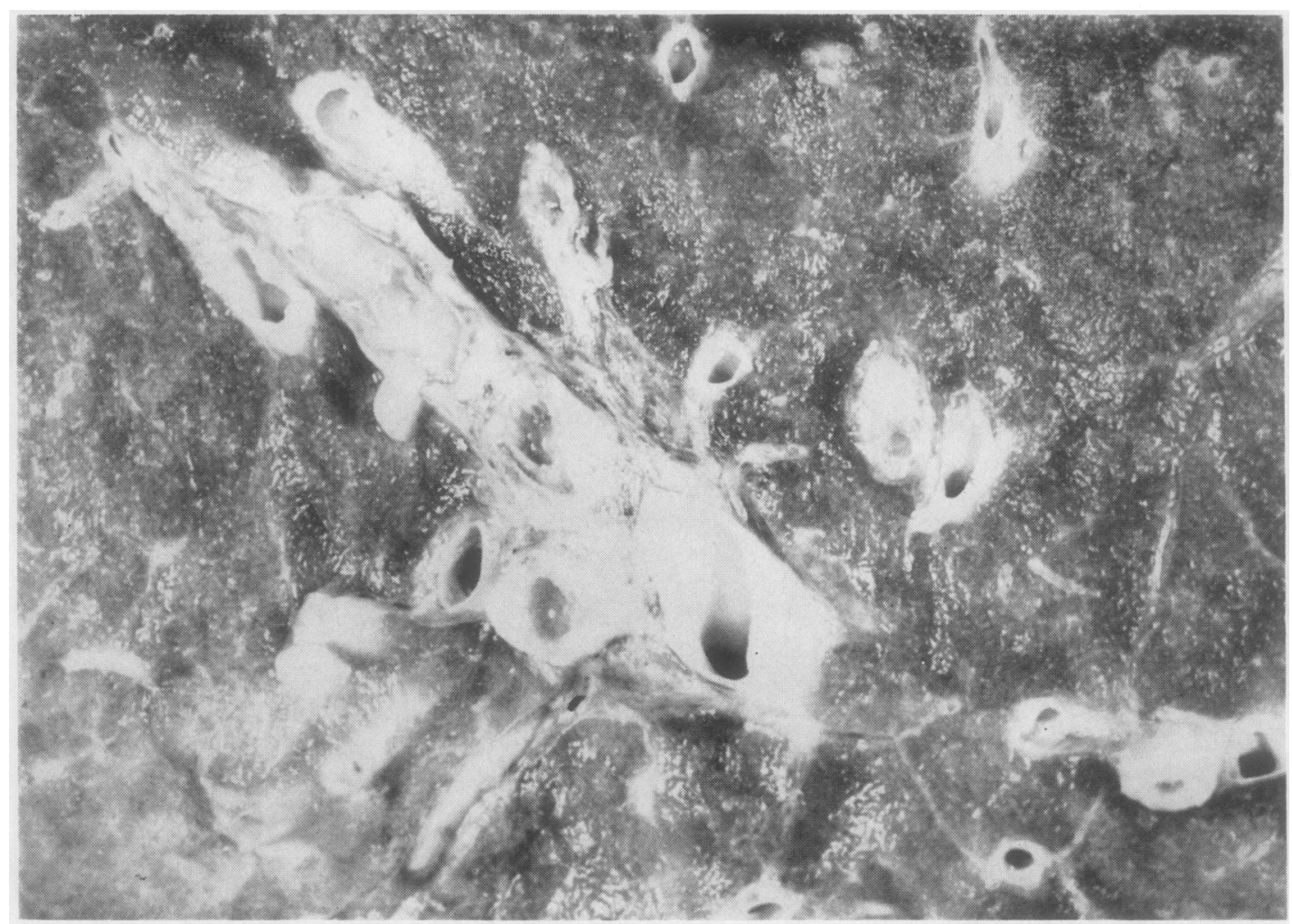

FIG. 1.-Cut surface of lung from Case 6 showing mucus plugs in medium-sized bronchi, $\times 1$.

the periodic-acid-Schiff method, by Robb-Smith's reticulin method, with Masson's trichrome stain, and with phosphotungstic acid haematoxylin. Some clinical details of the cases are given in the table.

\section{Gross Findings in the Lungs}

The appearances of the lungs at necropsy when death has resulted from status asthmaticus are characteristic. On opening the thoracic cage it is at once apparent that both lungs are acutely distended. They fill the chest, completely covering the pericardium, nearly meeting in the midline anteriorly, and failing to collapse once the negative intrathoracic pressure has been released. Gough (1955) has likened them to the lungs in drowning. In the cases examined in this series, bullous, centrilobular, or focal emphysema was not found in a single instance. A frequent but not invariable finding was the presence of small focal areas of collapse, and these were seen in Cases 1, 2, 3, 5, 7, 10,11 , and 18 . They were not confined to one surface or lobe of the lung but were seen just as frequently along the anterior margins and at the apices as at the bases. They appeared as firm, dark, airless, segmental areas depressed below the level of the distended lung.

The cut surface of the lung showed a striking picture with numerous grey, glistening mucous plugs scattered throughout the air passages (Fig. 1). These plugs were always seen in the small bronchi, but in some cases extended up to and occluded a main bronchus. In Case 8 both main bronchi were tightly packed with viscid mucoid material, and, in spite of the fact that intratracheal perfusion with formol saline under a pressure of 5 feet of water was attempted, little or none entered the lung. More often, however, a few segments became distended by fixative while the rest of the lung stayed distended with air.

In Cases $8,11,15$, and 17 areas of cystic bronchiectasis were present. The asthmatic is peculiarly prone to develop bronchiectasis, because if a bronchus is completely occluded absorption collapse of the lung distal to it will result. Bronchiectasis quickly follows this state, as Lee Lander and Davidson (1938) have shown. Evidence that this is the mechanism involved in the production of bronchiectasis in asthmatics is 


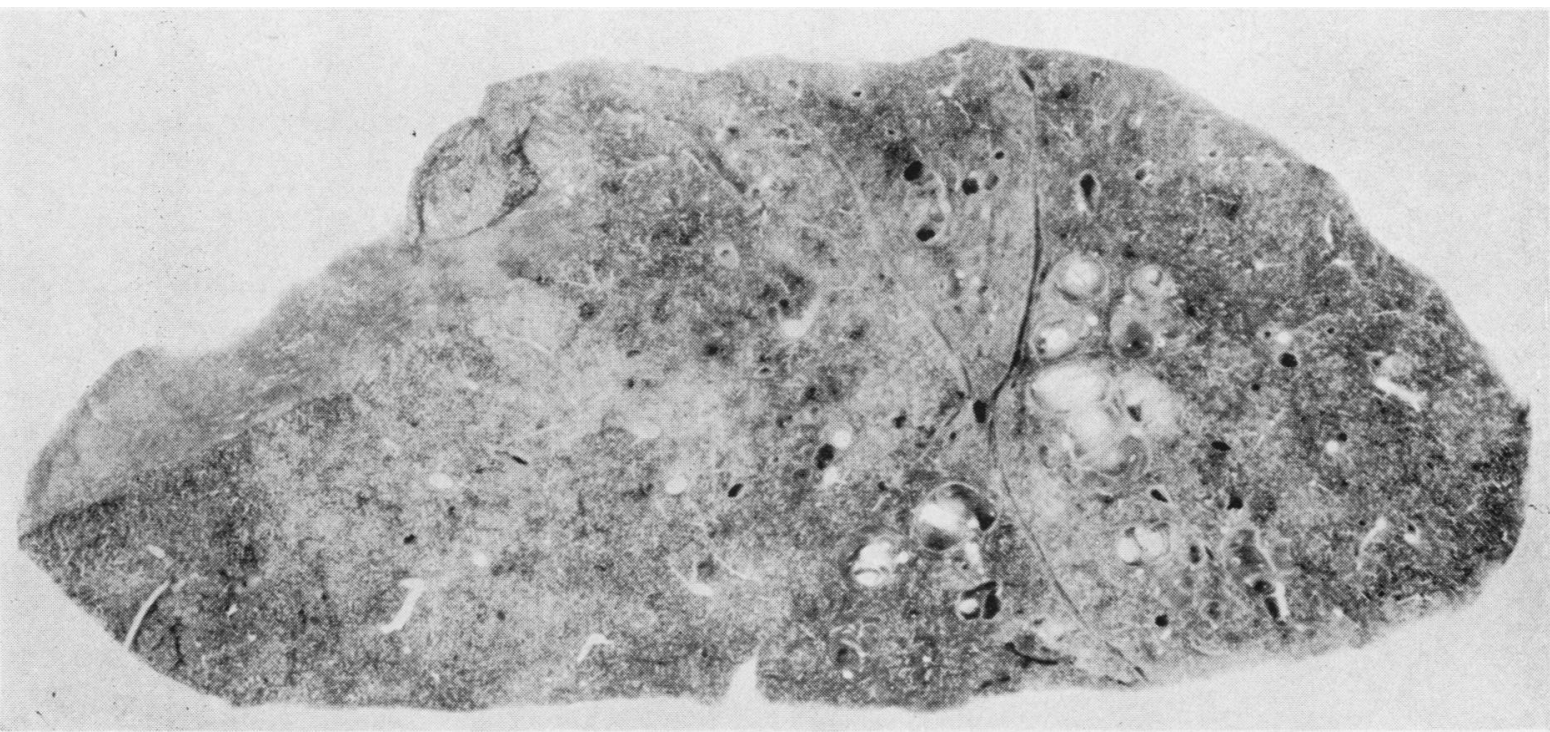

FIG. 2.-Cut surface of lung in Case 15 showing cystic bronchiectatic spaces in upper lobe and apex of lower lobe, $\therefore \frac{1}{3}$.

provided by the distribution of the lesions in the lungs studied. The upper and middle lobes or apex of the lower lobe were as often affected as the basal segments of the lower lobes (Fig. 2); the lesions thus followed a distribution similar to the focal areas of collapse already mentioned. The changes seen in the bronchi described in this paper do not, however, concern the mucosa of the bronchiectatic spaces. One further point of interest with reference to the cases showing bronchiectasis is that these were the only cases with any degree of right ventricular hypertrophy. Liebow, Hales, and Lindskog (1949) have shown that large precapillary bronchopulmonary arterial anastomoses occur in bronchiectasis, and it has been suggested that this is an important factor in the causation of pulmonary hypertension and right ventricular hypertrophy in this condition.

\section{Histology}

Lumen of the Respiratory Passages.-The most striking feature in any section from an asthmatic lung is the presence of a dense exudate in the bronchial lumen (Fig. 3). This can be seen as an occluding plug in the segmental bronchi, but it may extend distally as far as the respiratory bronchioles. The appearance of the exudate in haematoxylin-and-eosin preparations is somewhat variable. There is a mass of basophilic mucoid material, in which spirals of cells are entwined, but often areas of the exudate have a more eosinophilic appearance. Sections stained by the
periodic-acid-Schiff method show that only the basophilic parts of the exudate are strongly positive. The eosinophilic part of the exudate is presumably proteinacious in character; it does not give the staining reactions of fibrin with phosphotungstic-acid-haematoxylin or Masson's trichrome.

The cellular content of the exudate consists of eosinophils which are scattered fairly evenly throughout the mucoid portion and some epithelial cells. The possibility of the ep.thelial cells being a post-mortem artefact was considered, as these cells undoubtedly do become detached easily after death, particularly if fixation is inadequate. The idea was rejected, however, as in places the cells are so intimately mixed with mucus. In addition they sometimes appear in the centre of the exudate in a bronchus with a normal lining mucosa indicating that they have come from another part of the bronchial tree. These mucosal cells appear singly or in groups, and they may be normal ciliated columnar cells or goblet cells.

Another point in connexion with the exudate worthy of note is the paucity of neutrophil polymorphonuclear leucocytes. Histologically in none of the cases, including those with bronchiectasis, was there evidence of acute pyogenic infection.

Mucous Membrane of the Bronchi.-In some areas the bronchial mucosa may appear normal, but in those bronchi plugged with exudate there are obvious pathological changes. Commonly 


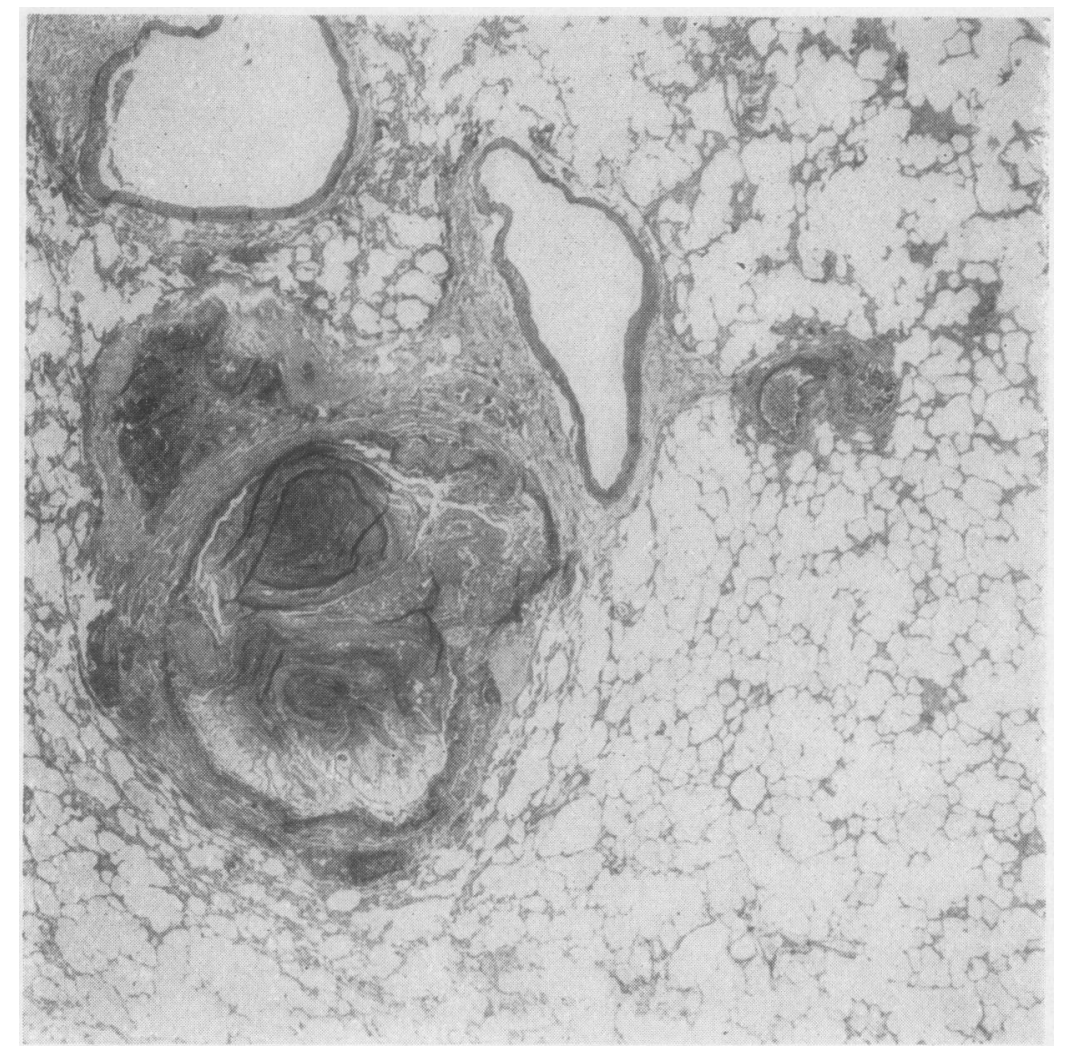

FIG. 3.-Low-power view showing bronchus plugged by exudate in Case 7. Note the absence of emphysema in the surrounding lung. Haematoxylin and eosin $\times 14$.

there is a marked degree of mucosal oedema with separation of the superficial columnar cells (Fig. 4). Eventually these cells become detached, and the remaining mucosa consists only of a few reserve or basal cells (Fig. 5). More interesting still are areas of regeneration which can be seen at focal points in the bronchial wall. Mitotic activity among the deeper cells is increased, and the epithelium is of the simple stratified type (Figs. 6 and 7). These areas were seen in all cases, but were much more marked in some than others. In Case 8 all the bronchi examined were lined by this metaplastic or regenerating epithelium. The appearances are very reminiscent of those seen by Wilhelm (1953) and Otto and Wagner (1956) when the trachea and bronchi were undergoing repair following experimental trauma. In the asthmatic lung these areas represent places where the mucosa has become detached and repair is taking place. All stages can be seen, from areas where only a few basal cells are present, through areas of metaplasia with simple stratified epithelium, to the normal pseudo stratified columnar, ciliated, respiratory epithelium. These metaplastic cells have recently been detected in the sputum of asthmatics by Cohen and Prentice (1959).

Eosinophils can be seen occasionally in the intact but oedematous bronchial mucosa, and presumably diapedesis of these cells occurs through the mucosa.

One of the most pronounced changes in the bronchial wall is the thickening of the basement membrane. This was seen in all except the two youngest patients in the series, Cases 1 and 2 . It presents as a thick eosinophilic band to which the cells of the bronchial mucosa are closely applied. The membrane stains red in van Gieson preparations, green with Masson's trichrome, and pink with the P.A.S. technique. In sections stained for reticulin it is black, but sometimes, particularly in those cases where it is greatly thickened, it has a brownish collagenous component. In chronic bronchitis the basement membrane becomes thickened, but thickening is more variable and never so pronounced as in asthma.

Beneath the basement membrane, apart from the infiltration by eosinophils, the most striking feature is the dilatation of the capillary blood 


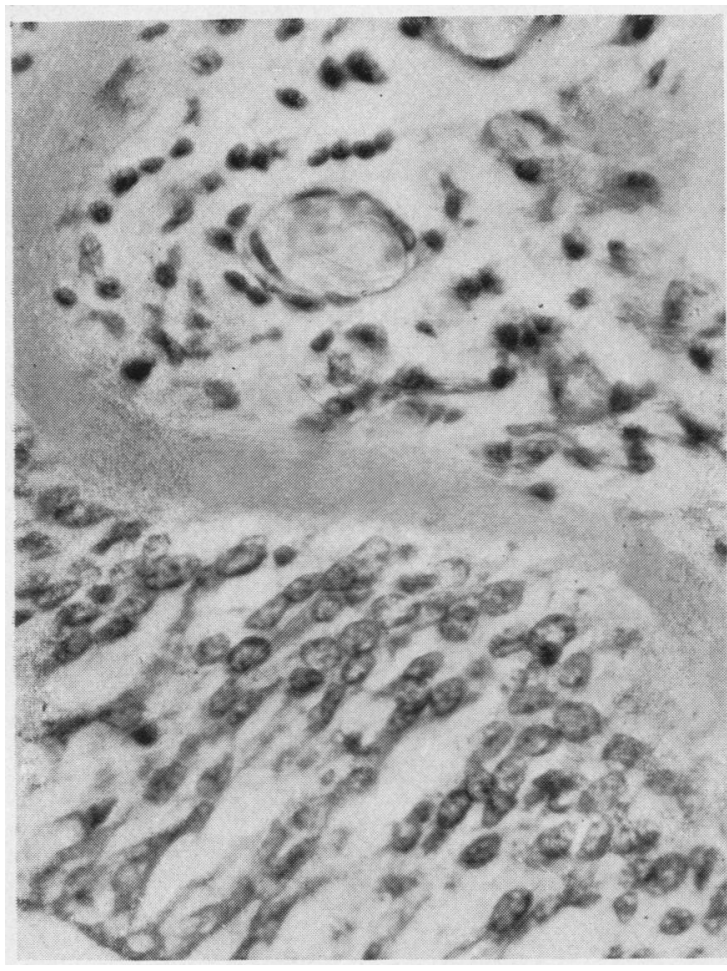

Fig. 4. - Section of a medium-sized bronchus in Case 7, showing mucosal and submucosal oedema. Haematoxylin and eosin, $\times 400$.

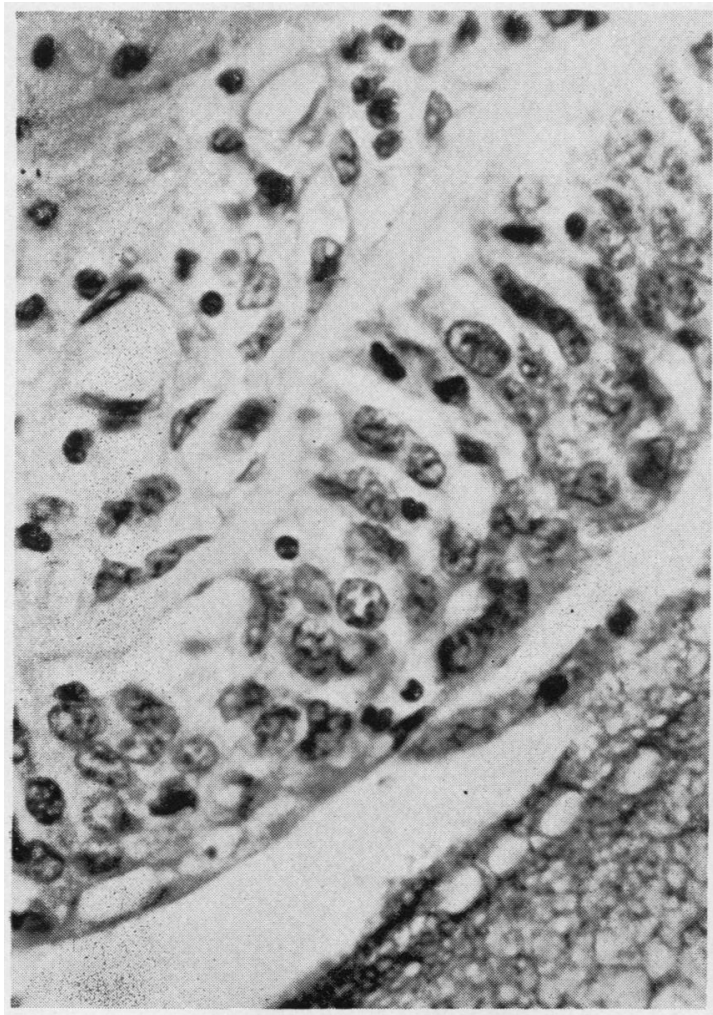

FiG. 6. Section showing medium-sized bronchus lined by simple stratified epithelium. Haematoxylin and cosin, $\times 400$.

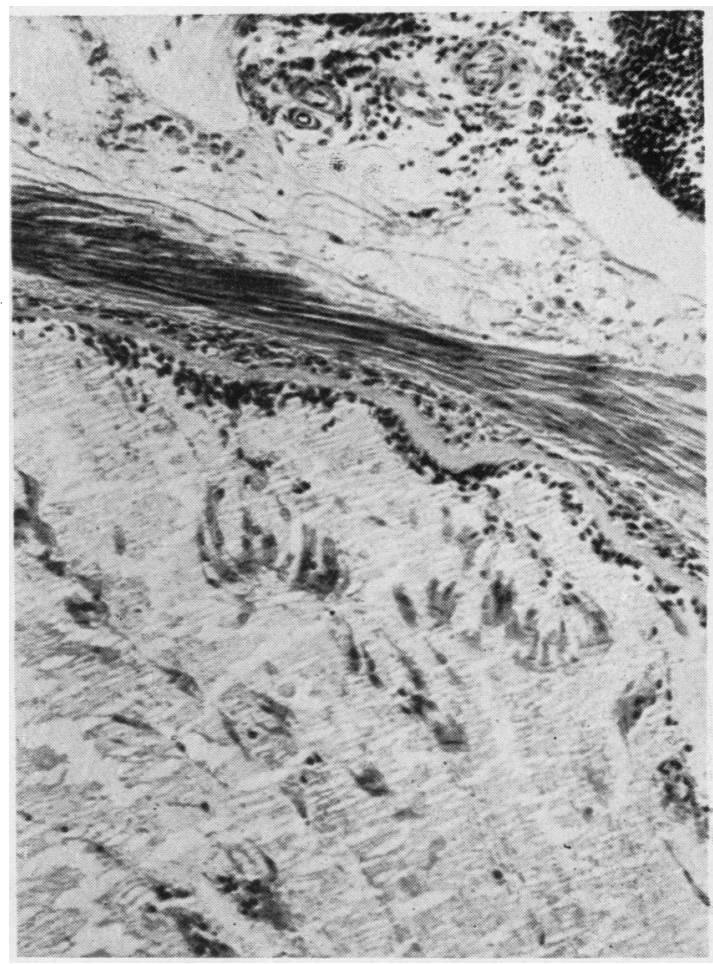

FIG. 5.-Section showing a medium-sized bronchus lined by reserve or basal cells only. Columnar and ciliated cells are present in the exudate. Haematoxylin and eosin, $\times 112$.

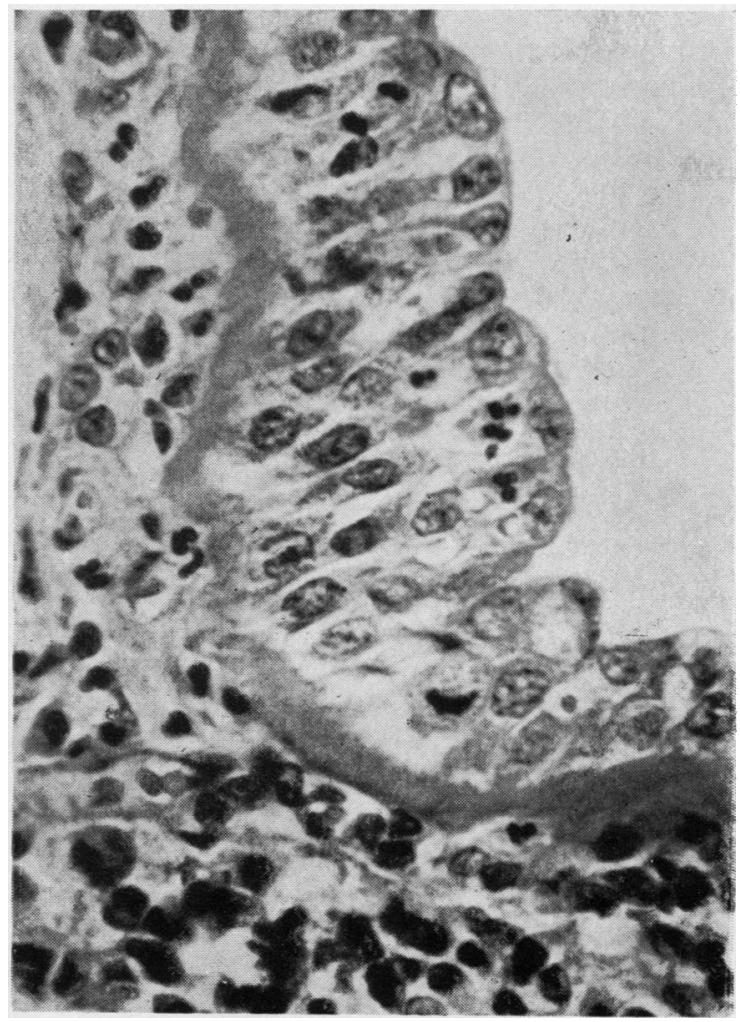

Fig. 7.-Commencing redifferentiation of bronchial epithelfum with marked mitotic activity. Note the thickened basement membrane. Masson's trichrome, $\times \mathbf{4 0 0}$. 
vessels. These vessels, often possessing rather swollen endothelial cells, are closely applied to the basement membrane. The connective tissue in which these vessels lie consists of strands of widely separated collagen giving the impression of oedema (Fig. 4). Furthermore, the mucosa overlying these areas often shows oedema with separation of the cells. It is interesting to note that Wilhelm (1953) found that prominent submucosal inflammation, following removal of the tracheal epithelium, prolonged mitotic activity in the regenerating epithelium and delayed its differentiation.

The Bronchial Wall.-The mucous glands appear active but not hypertrophied as they are in chronic bronchitis (Reid, 1954).

The smooth muscle in the walls of the bronchi, especially those of $0.4-0.6 \mathrm{~mm}$. diameter, shows considerable hypertrophy. Crenation of the bronchial mucosa of the type seen in animals dying of anaphylactic shock (Dixon and Warren, 1950), and said to indicate bronchospasm, was not noted. Indeed, the smaller bronchi and the bronchioles appeared if anything rather dilated (Fig. 3) with the bronchial wall stretched over the cense exudate in the lumen. In some of the large air passages it is true that irregularities can be seen in the bronchial mucosa with the formation of diverticula. Frequently these represent the mouths of the mucous gland ducts, and this can be demonstrated by serial sections. In other cases they may possibly represent the contraction of the bronchial smooth muscle, but even so it is difficult to credit that they would affect the diameter of the air passages in which they are present.

\section{Discussion}

In a recent lecture Young (1959) cited three main factors in the production of an asthmatic attack: (1) Spasm of the smooth muscle of the bronchi, (2) swelling of the mucous membrane, and (3) production of excessive glairy mucus. Clinically the concept of bronchospasm depends upon the auscultatory sign of a high-pitched expiratory rhonchus or wheeze. This is a sound produced in an air passage due to partial occlusion of its lumen, and there is nothing in the sound itself to differentiate obstruction by oedema of the bronchial mucous membrane, or by mucus, from spasm of the bronchial muscle. Anatomical evidence that asthma is due to bronchospasm is based, first on the presence of hypertrophied smooth muscle in the bronchial wall, and secondly on the doubtful finding of the crenation of the bronchial mucosa.
There is ample evidence for the allergic origin of bronchial asthma in its association with hay fever and urticaria, the frequency of eosinophilia in the peripheral blood, and positive skin sensitivity tests to foreign proteins. Segal and Attinger (1957) have stated that the allergic reaction is associated with (1) capillary dilatation, (2) increased capillary permeability, (3) increase in the protein content of intercellular fluid, (4) engorgement of lymphatic and blood capillaries, (5) accumulation of eosinophils, and (6) accumulation of mucus secretion in the walls of the bronchioles. The anatomical counterparts of these six points can be clearly seen in the submucosa of the bronchi where there is oedema and capillary dilatation.

Pathologically the outstanding feature of the asthmatic lung lies in the failure of clearance of the bronchial secretions. Two factors are implicated in this, first the "glairy" quality of the mucus itself, and secondly the loss of ciliary action in the bronchial mucous membrane. Florey (1958) has pointed out that the exudate from an inflamed mucous membrane consists not only of mucus produced by glands in the wall and by goblet cells but also of a protein-laden transudate which arises from the increased permeability of the dilated capillaries in the submucosa. A similar process seems likely to cccur in asthma. It has already been noted that the exudate in the bronchial lumen is not homogeneous and only partly mucoid in nature. In fact this is in keeping with the allergic basis of the disease. The dilated capillaries lie in oedematous connective tissue just below the basement membrane, and some of the oedema fluid must pass through the mucosa into the bronchial lumen. The presence of this serous fluid exudate closely applied to the bronchial mucosa will affect the ciliary action of the mucosal cells. Hilding (1932) has shown that serous fluid severely curtails the action of cilia, which are much more effective when dealing with pure mucus.

Movement of the exudate will also be retarded $N$ by the shedding of the mucosal cells, which was a N noticeable feature in this series and was also $O$ emphasized by Houston et al. (1953). The explanation offered by these authors for the detachment of the mucosal cells was that it is due $\stackrel{\oplus}{\rightarrow}$ to muscle spasm and consequent crenation of the $T$ mucous membrane with mechanical separation of the epithelium. A more likely factor in this $\mathbb{D}$ disturbance of the mucosa would be the $\frac{}{\mathbb{1}}$ transudation of oedema fluid across the mucous membrane. There is no situation in human 
pathology where contraction of smooth muscle causes detachment of an epithelial surface, but in the skin, e.g., in eczema and the bullous eruptions, disorganization of epithelial architecture by oedema with underlying capillary dilatation, increased capillary permeability, and transudation of protein-laden fluid is commonplace. Disturbances of epithelial continuity are even more likely to occur in the delicate respiratory mucosa following allergic submucosal oedema.

The submucosal oedema may also play some part in the thickening of the bronchial basement membrane. Robb-Smith (1952) has suggested that hyalinization of the basement membrane in the nasal mucosa, following numerous attacks of inflammation, is related to the accumulation of plasma protein and mucopolysaccharide in the inflammatory oedema fluid. Resolution of this oedema results in a condensation of these protein complexes to form "hyaline." A similar mechanism might apply in asthma with continual formation and resolution of submucosal oedema.

It is sometimes claimed that bronchospasm must play some part in the production of an asthmatic attack because of the therapeutic action of adrenaline which relaxes the bronchial smooth muscle. Sheldon and Otis (1951) have shown that an increase in the vital capacity in an asthmatic after adrenaline has been given is not always accompanied by a decrease in air flow resistance as would be expected if adrenaline relaxed the bronchial smooth muscle. They consider that adrenaline acts as a vasoconstrictor on the pulmonary and bronchial arteries, thereby decreasing the quantity of blood in the thorax and allowing more room for air. In some cases air flow resistance is decreased, and here adrenaline may constrict the dilated vessels in the bronchial submucosa, thereby decreasing mucus secretion and submucosal oedema. An explanation for the hypertrophied bronchial musculature may be found in the hypothesis that in cases where ciliary action is defective or absent this muscle plays some part in clearing the bronchial secretions by peristaltic contractions, as suggested by Holden and Ardran (1957) in a bronchographic study using cineradiology. In asthma where ciliary action is so deficient this muscle would undergo a work hypertrophy.

I am grateful to Dr. A. H. T. Robb-Smith for reading the manuscript and for much helpful d:scussion during the preparation of this paper. Mrs. D. Jackson took the photographs and Miss $M$. Reading gave technical assistance.

\section{REFERENCES}

Cohen, R. C., and Prentice, A. I. D. (1959). Tubercle (Lond.), 40, 44 Curschmann, H. (1883). Dtsch. Arch. klin. Med., 32, 1.

Dixon, F. J., and Warren, S. (1950). Amer. J. med. Sci., 219, 414 Ellis, A. G. (1908). Ibid., 136, 407.

Florey, H. W. (1958). In General Pathology, ed. H. W. Florey, 2nd ed., p. 120. Lloyd-Luke, London.

Gough, J. (1955). Lancet, 1, 161 .

Hilding, A. (1932). Amer. J. Physiol., 100, 664

Holden, W. S., and Ardran, G. M. (1957). J. Fac. Radiol. (Lond.) 8, 267.

Houston, J. C., De Nevasquez, S., and Trounce, J. R. (1953). Thorax, $8,207$.

Lander, F. P. L., and Davidson, M. (1938). Brit. J. Radiol., 11, 65. Liebow, A. A., Hales, M. R., and Lindskog, G. E. (1949). Amer. J. Path., 25, 211.

Otto, H., and Wagner, H. (1956). Beitr. path. Anat., 116, 436.

Reid, Lynne McA. (1954). Lancet, 1, 275.

Robb-Smith, A. H. T. (1952). Proc. roy. Soc. Med., 45, 811

Segal, M. S., and Attinger, E. O. (1957). In Clinical Cardiopulmonary Physiology [American College of Chest Physicians], ed. B. L. Gordon, p. 283 et seq. Grune and Stratton, New York

Gordon, p. 283 et seq. Grune and Stratton, New York.
Sheldon, M. B., and Otis, A. B. (1951). J. appl. Physiol., 3, 513.

Wilhelm, D. L. (1953). J. Path. Bact., 65, 543.

Young, F. H. (1959). Chest and Heart Bull., 8, 42. 